\title{
QUERELAS DE ONTEM, QUERELAS DE HOJE: A TEORIA DA LITERATURA COMO DESAFIO À FORMAÇÃO DO LEITOR
}

Tarsilla Couto de Brito*
* tarsillacouto@gmail.com

Professora da Faculdade de Letras da UFG.
RESUMO: A oposição entre Estudos Culturais e Teoria da Literatura ficou conhecida na historiografia recente como uma batalha anti-humanista construtivista (FREADMAN \& MILLER 1992); nas instituições de ensino norte-americanas recebeu o título de Guerra Cultural, cuja natureza e repercussão foram comparadas às da Querela francesa do século XVII (DEJEAN 1997). A análise das consequências desse debate para os estudos literários brasileiros,contudo, ainda não se realizou. E notório que o conflito teórico, no Brasil, afetou não apenas as investigações acadêmicas, mas também as políticas públicas voltadas para a formação do professor de literatura e, consequentemente, as práticas de ensino de leitura literária. A comparação entre os documentos que oficialmente orientam a postura do professor (Parâmetros Curriculares Nacionais de 2000 e 2002 e Orientações Curriculares de 2006) demonstra teoricamente como absorveu-se o debate: o Ensino de Literatura no Brasil entrou em crise. O objetivo deste artigo é alcançar uma pequena amostragem das consequências práticas dessa querela teórica.

PALAVRAS-CHAVE: Ensino de Literarura; Querelas Literárias; PCN.
RÉSUMÉ: L'opposition entre les études culturelles et théorie littéraire est devenu connu dans l'historiographie récente comme une bataille constructiviste anti-humaniste (FREADMAN \&MILLER, 1992); dans les établissements scolaires américains ont reçu le titre de la guerre culturelle, et la nature et l'impact ont été comparés à la Querelle français du XVIle siècle (DEJEAN, 1997). L'analyse des conséquences de ce débat pour les études littéraires brésiliens, cependant, ne est pas encore réalisé. II est clair que le conflit théorique au Brésil a affecté non seulement les inverstigações académiques, mais aussi les politiques publiques visant à la formation du professeur de littérature et par conséquent les pratiques d'enseignement de la lecture littéraire. La comparaison entre les documents officielles a guide la position de l'enseignant (PCN de 2000 et de 2002 et OC de 2006) et a montre comment théoriquement repris le débat: la littérature éducation au Brésil était en crise. Le but de cet article est de réaliser un petit échantillon des conséquences pratiques de ce différend théorique.

MTS-CLÉS: Enseignement Literarura; Querelles littéraires; PCN. 


\section{APRESENTAÇÃO}

A discussão que agora proponho como professora recém efetivada na Faculdade de Letras da Universidade Federa de Goiás surgiu em minha última experiência de substituição ocorrida na mesma instituição nos anos de 2011 e 2012 Regendo turmas de estágio em língua portuguesa, percebi que ao final de cada um dos seguintes semestres de 2011-1, 2011-2, 2012-1, 2012-2, os relatórios apresentados:

1. Revelavam uma singular dificuldade de relacionar a teoria literária e a crítica literária oferecidas por outras disciplinas da grade curricular com a prática da sala de aula - que resultava quase sempre na dificuldade e/ou insegurança de elaborar uma atividade de leitura literária de forma autônoma

2. Denunciavam o desinteresse generalizado dos professores regentes das Escolas Campo observadas pela literatura dita canônica ou pelos gêneros considerados difíceis - é possíve identificar aí um discurso relativamente cristalizado sobre "a importância da literatura" em contradição com outro discurso cristalizado "o povo não gosta de ler coisa boa";

3. Registravam planos de aula de literatura cujos objetos pertenciam à Indústria Cultural (como filmes e letras de música pop) ou à Cultura popular (como lendas, poesia de cordel, contos populares) - os relatórios analisados apresentam um dissenso sobre esse tópico: parte defende que se deve ceder a esse tipo de "populismo literário" em nome de aproximar-se da "realidade dos alunos" e parte acredita que essas práticas de leitura apenas repetem a experiência que o jovem já tem fora da escola, dissolvendo, alguns falam em anulação, do sentido da palavra literatura;

4. Destacavam práticas de leitura literária, mais especificamente, exercícios de crítica literária de cunho moralizante, deixando subentendida uma concepção distorcida de beletrismo de que literatura teria função de "melhorar as pessoas". Para os alunos estagiários ficava o conflito sobre que critério de qualidade ou de juízo de valor deveria ser adotado na seleção dos textos e livros literários para suas futuras turmas.

5. Assinalavam também planos de aula diversos em que textos literários da tradição eram apresentados em fragmentos (trechos de romances, de contos e de poemas) com finalidades alheias à leitura literária tais como identificação de regras gramaticais para aulas de Língua Portuguesa ou de contextos históricos para aulas de História.

\section{CRUZANDO OLHARES}

Com o tempo esse conjunto de problemas, que aparentemente estava restrito ao contexto formativo dos professores do Estado de Goiás, começou a revelar-se para mim como conectado com outros circuitos dos estudos literários no Brasil e no exterior. 
Paralelamente à essa experiência com o processo de formação de professores de leitura literária, eu concluía minha pesquisa de doutorado sobre as ideias pedagógicas de Fénelon desenvolvidas no século XVII e seu envolvimento com a Querela entre Antigos e Modernos que se desenrolou durante o reino de Luís XIV.

A primeira iluminação que o famoso afair do Classicismo francês me ofereceu foi a própria noção de Querela. Tradicionalmente usado na História da literatura para designar controvérsias artísticas ou culturais prolongadas sobre um determinado tema, a palavra Querela passou a significar para mim uma perspectiva, um modo de ver as coisas.

Quando você estuda uma corrente crítica, por exemplo, a fenomenologia, você pode com facilidade defini-la como uma espécie de método que faz a mediação entre o sujeito e o objeto ou, dizendo de outro modo, entre o eu e a coisa. A partir da concepção que se deseja emprestar à realidade, ou à coisa, se podem distinguir três grandes linhas na fenomenologia: a transcendental, husserliana, a existencial, a partir de Jean-Paul Sartre e Maurice Merleau-Ponty, e a hermenêutica, cujos representantes maiores seriam Hans George Gadamer e Martin Heidegger. Você pode verticalizar o conhecimento a partir de diferentes autores sem perceber que essa teoria está em constante tensão com outras teorias, que critica outras teorias e delas recebe crítica.
Quando se estuda uma Querela, é impossível ignorar o conflito, o debate, a réplica, a tréplica. Quando se estuda uma Querela, você é obrigado a procurar saber muito de pelo menos duas correntes críticas/teóricas. E o mais importante, você percebe a relação direta entre teoria e vida prática, pois você finalmente enxerga que um intelectual, quando defende um livro, uma ideia, uma obra de arte, ele faz isso em nome de uma convicção política. Daí a minha adesão ao estudo de querelas e não apenas de sistemas teóricos. Trata-se de uma opção pelo estudo do diálogo desestabilizador e não do monólogo, que pode ser difícil, mas é sempre mais seguro. Além disso, a perspectiva da querela é muito afim ao tema da crise. As grandes querelas da modernidade foram sintomas de crises sociais ou epistemológicas divisoras dos quais a sociedade emergiu com significativas transformações.

Os olhares cruzados sobre a escola, e, mais especificamente sobre a formação de professores de literatura, que me inspiram nesta pesquisa, partem do princípio da analogia e, por conseguinte, aponta homologias estruturais de transição dos modelos de conhecimento disponíveis sobre literatura no século XVII como hoje. Tanto a transição vivida pela Academia francesa no século XVII quanto a transição experimentada pela cultura ocidental a partir da segunda metade do século XX desenvolveram discursos de crise: crise da literatura, crise do ensino, crise do humanismo. 
O primeiro sinal dessa crise, como acabei de descrever, veio para mim das minhas turmas de professores em formação: afirmações provocativas do tipo "literatura não serve para nada" ou perguntas sinceras como "por que eu sou obrigado a gostar de Guimarães Rosa e não posso gostar de Paulo Coelho?" eram formuladas pelos próprios alunos de Letras. Em 2010, contudo, um evento nacional ampliou o horizonte dessa crise.

Ficou famosa a polêmica acerca da presença (ou ausência) de estereótipos raciais na obra infantil de Monteiro Lobato conhecida como Caçadas de Pedrinho. O caso chegou ao Supremo Tribunal Federal por meio de um mandado de segurança apresentado pelo Instituto de Advocacia Racia (Iara). Afirmava-se que a obra de Monteiro Lobato possui "elementos racistas". Em 2010, o Conselho Nacional de Educação (CNE) determinou que o livro de Lobato não fosse mais distribuído às escolas públicas. $O$ conselho apresentava trechos da obra para justificar o veto: “Tia Nastácia, esquecida dos seus numerosos reumatismos, trepou, que nem uma macaca de carvão”. Em seguida, o Ministério da Educação (MEC) recomendou que o CNE reconsiderasse a determinação. O conselho decidiu então anular o veto e indicar que as futuras edições do livro viessem acompanhadas de uma nota técnica que instruísse o professor a contextualizar a obra ao momento histórico em que ela foi escrita.
Está em jogo aqui um problema fundamental tanto para a teoria quanto para a crítica literária: o problema do juízo de valor e, consequentemente, do cânone literário escolar. Em nosso presente, a pergunta seria formulada assim: "Um texto literário de qualidades estéticas reconhecidas pela crítica deve ser eliminado do cânone em razão de seu conteúdo politicamente incorreto?" Os acadêmicos do século XVII viveram o mesmo tipo de confronto quando, em 1633, o Bispo de Vences publicou suas Oeuvres chrétiennes com as quais convocava todos os poetas do reino apenas obras de inspiração cristã. Houve vários tipos de respostas. Corneille chegou a afirmar que as coisas santas não deveriam ser usadas em obras de arte como fábulas e peças de teatro. Desmarets de Saint-Sorlin, por sua vez, declarava-se, dali por diante, contra qualquer sorte de poesia pagã ${ }^{1}$. Assim, os partidários dos Antigos defendiam a separação entre arte e Cristianismo e os dos Modernos apostavam numa arte cristã.

A polêmica sobre As caçadas de Pedrinho tem caráter completamente laico e se inscreve em outro tipo de contexto moralizador. Mesmo assim, o fundo moral da contenda permanece: há ainda uma confusão entre bem e belo que devemos resolver. A iniciativa de solicitar a interferência do Poder Judiciário na política de edição e de distribuição de livros literários adotada pelo Programa Nacional Biblioteca na Escola (PNBE) sob a chancela do MEC deve ser compreendida na chave da inserção dos Estudos Culturais nas

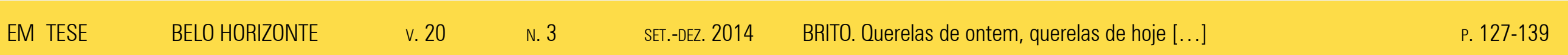


academias de Letras e de Ciências Humanas no Brasil, posto que se trata da corrente de pensamento moderna que coloca em xeque o conceito elitista de belo do humanismo cristão e platônico que nos domina culturalmente há mais de dois mil anos.

Sobre as orientações oficiais para o ensino de literatura no Brasil

A crise do ensino de literatura revela sua face institucional quando lemos em perspectiva comparativista os dois últimos documentos oficiais de orientação ao professor publicados pelo Governo Federal. Em 2002 o MEC publicou uma nova versão dos Parâmetros Curriculares Nacionais que assumia explicitamente uma concepção de linguagem denominada como "sócio-pragmática e discursiva". As implicações teóricas dessa concepção para a reflexão sobre literatura apresentaram-se assim:

Ao ler este texto, muitos educadores poderão perguntar onde está a literatura, a gramática, a produção do texto escrito, as normas. Os conteúdos tradicionais foram incorporados por uma perspectiva maior, que é a linguagem, entendida como espaço dialógico, em que os locutores se comunicam. ${ }^{2}$

É inegável que o conceito de dialogismo, nos termos bakhtinianos, representou uma conquista teórica tanto para os Estudos Literários quanto para a Linguística. Como tantos outros conceitos, todavia, o dialogismo não escapou da distorção inerente aos processos de difusão do conhecimento. $\mathrm{O}$ ensino de literatura era, desse modo, tragado por uma concepção de linguagem generalista que, ao afirmar a literatura como mais um discurso entre os diversos discursos circulantes na comunidade letrada ocidental, terminava por justificar atividades de leitura sem especificidade literária.

As práticas de leitura culturalistas, segundo Maria Eliza Cevasco $^{3}$, propõem-se como atividades lúdicas de inclusão e de aceitação da diferença e da diversidade nas representações culturais e literárias. O sentimento de pertença, entende-se, perpassa o processo de leitura e de formação do leitor. Assim, a leitura (literária ou não) definir-se-ia como uma prática social que possibilita uma pedagogia da inclusão em que o estético e o social não estão separados, posto que a leitura aproxima o leitor da produção cultural de diferentes épocas, da experiência de cultura de variadas comunidades.

Foi em nome de uma concepção de cultura mais ampla e democrática, em nome dessa compreensão de leitura que busca a igualdade e o respeito entre todos os brasileiros que o IARA (Instituto de Advocacia Racial e Ambiental) entrou, em 2010, com um mandado de segurança solicitando a suspensão da distribuição do livro de Monteiro Lobato.
3. CEVASCO, Dez lições sobre os estudos culturais.
EM TESE
BELO HORIZONTE
v. 20
SET.-DEZ. 2014
BRITO. Querelas de ontem, querelas de hoje [...]
P. $127-139$

Ensino de literatura e de Teoria da Literatura 
Mas antes de avançar a reflexão sobre a querela do racismo em As caçadas de Pedrinho, é preciso ao menos resumir as novas orientações para ensino de Literatura publicadas pelo MEC em 2006. No texto, o espírito de conflito está posto, as críticas desfavoráveis ao documento anterior são explícitas. Uma leitura comparada entre os PCN's permite verificar uma clara distinção entre a fundamentação teórica culturalista do documento de 2002 e o caráter humanista do texto de 2006. Este documento mais recente foi escrito e avalizado como uma tentativa de romper com o estado de crise em que se encontrava o ensino de literatura - a crise se caracterizaria pela não ausência de um esforço de leitura efetiva de uma literatura considerada difícil e ainda pela incompetência para a análise (lembrando que a análise foi a melhor lição do estruturalismo) e para a interpretação (praticada com excelência pela fenomenologia e pela hermenêutica) do texto literário.

\section{OUTROS SINAIS DE CRISE}

Parece que foi de repente: o que teria levado Calvino a escrever um texto que explicasse "Por que ler os clássicos" (Italo Calvino para o jornal L'Espresso em 1981)? Aquilo que sempre se apresentou como óbvio - ler "um livro que se configura como equivalente do universo, à semelhança de antigos talismãs" (Calvino, 2007, p. 13) - já não revela por si só uma boa justificativa para a leitura do que tradicionalmente chamamos "literatura".
A iniciativa de Calvino, contudo, não é exatamente uma profecia da crise que se instauraria no final do século XX. Antes dele, em 1948, Sartre concluía sua resposta para "O que é literatura" afirmando: "Nada nos garante que a literatura seja imortal [...] o mundo pode muito bem passar sem a literatura" ${ }^{4}$. E ainda antes, Rimbaud já não tinha desistido da literatura? A crise parece ter-se constituído como o desdobramento inevitável de uma concepção de literatura que durante mais de dois séculos perseguiu o desejo de ser ela mesma crise, crítica e transformação.

Alguns dados da realidade podem comprovar que os discursos desqualificadores da literatura têm prejudicado os estudos literários desde as últimas décadas do século XX Apesar de ter se tornado um mito - pois escritores continuam escrevendo, leitores continuam lendo - tanto as lamentações quanto as celebrações da morte da literatura produziram consequências práticas para a vida intelectual acadêmica no Ocidente e, mais especificamente, para todo o aparato mobilizado pelo projeto de formação de leitores desde o mercado editorial até a grade curricular do Ensino Básico no Brasil.

A crítica e a história literárias podem ser apontadas como as áreas de conhecimento sobre literatura que primeiro sofreram descrédito: em 1967, Hans Robert Jauss proferia a palestra que, transformada em livro, ficou conhecida no
4. SARTRE, Que é a literatura?, p. 217-218.
EM TESE
BELO HORIZONTE
v. 20
N. 3
SET.-DEZ. 2014
BRITO. Querelas de ontem, querelas de hoje $[\ldots]$
P. $127-139$

Ensino de literatura e de Teoria da Literatura 
Brasil como A História da literatura como provocação à Teoria literária. Sua intenção era alcançar uma síntese entre as conquistas e fracassos da crítica imanentista e da crítica marxista. Essa síntese encaminhar-se-ia a partir de uma renovação da história literária, naquele tempo como hoje, desabonada em seus métodos e objetivos.

Essa desconfiança da história literária justificava-se, por um lado, graças a sua associação com projetos nacionalistas e, quase que paralelamente, numa tentativa de desideologiazação a serviço de ideologias, graças a sua associação com projetos supratemporais de um cânone que deveria sustentar ideias de verdade e essência da tradição literária. Jauss propunha que deixássemos para trás a velha história da literatura e nos dedicássemos a uma contemplação da literatura na História. A figura do leitor nos ofereceria os parâmetros para tal exercício, que voltaria a ser estético.

O mesmo acontece com a crítica literária, atividade que ficou estigmatizada no imaginário pós-moderno como um tipo de erudição arrogante que se manifesta narcisisticamente sem rigor e sem finalidade. E mesmo quando conseguiu eliminar o subjetivismo de seu modus operandi, sem poder dizer da qualidade estética dos textos literários, a crítica precisou buscar outros critérios para justificar sua existência.

Em 1996, a professora Leyla Perrone-Moisés perguntava em artigo publicado na Folha de São Paulo, "Que fim levou a crítica literária?” (http://www1.folha.uol.com.br/fsp/1996/8/25/ mais!/14.html). A pergunta e todo o texto questionavam a pauta do Congresso da Associação Internacional de Literatura Comparada previsto para 1997 na cidade de Leiden, Holanda. Para Leyla Perrone-Moisés, se a literatura permanecesse restrita à ideia de "Memória cultural", a crítica literária estaria pulverizada, perderia sua razão de ser. A explicação para isso: quando o objeto literatura passa a ser visto como expressão, reflexo e/ou sintoma de uma cultura, perde sua dimensão de conhecimento e, consequentemente, a crítica perde sua função de descrever, interpretar e avaliar as relações entre o conhecimento proposto pela obra literária e a realidade.

A própria teoria da literatura, que surgiu em meados do século XX com objetivo de legitimar os estudos literários, terminou por receber seu atestado de óbito em Teoria da literatura: uma introdução (Terry Eagleton, 1983), livro que se transformou equivocadamente em um Manual para os estudantes de Letras. A principal razão para Eagleton declarar o fim da teoria reside no fato de não se poder definir o que é literatura sem prender-se a um parti pris interessado politicamente, ou seja, a uma ideologia. E se não há uma definição confiável, desinteressada de literatura, a teoria não faz sentindo algum. Desse modo, a teoria esteve condenada durante as últimas décadas a um "sem-lugar" cultivado pelo senso-comum onde se encontram todas as ideias que aparentemente não têm utilidade. 
Por fim, as obras literárias em si mesmas passaram a ser questionadas. A desconfiança dos modos de representação praticados sob a rubrica da literatura é resultado da convergência de todas as críticas feitas aos estudos literários anteriormente: pelos serviços prestados à consolidação de identidades nacionais (crítica feita à história e à história da literatura); pela manutenção de valores apresentados como essenciais para dominação de uma classe ou de uma ideologia (crítica feita também à história da literatura e, ainda, à crítica literária quando essas atividades precisam se haver com o problema do cânone); pela supervalorização das noções de indivíduo, de subjetividade, de identidade, de visão de mundo, de representação e de estilo - noções condenadas porque ignorariam o fato de que o mundo seria construído pela linguagem e que o EU não passaria de um conjunto de discursos determinados e determinantes.

Não é gratuito que importantes pensadores da literatura da contemporaneidade, em algum momento da virada do século XX para o XXI, preocuparam-se em escrever textos como A literatura em perigo (Tzvetan Todorov), Literatura para quê? (Antoine Compagnon), Humanismo e crítica democrática (Edward Said). Em vez de aceitar o luto, proponho a reinterpretação desses fenômenos como sinais de uma transformação cultural em que a literatura e a teoria da literatura continuam a jogar um papel importante.
A querela literária em torno de As caçadas de Pedrinho de Monteiro Lobato

A decisão de aprovar a permanência do livro de Lobato no cânone escolar com paratextos direcionadores da leitura a ser praticada causou celeuma: a mídia televisiva e impressa ocupou-se de divulgá-la; especialistas foram convocados a dar suas opiniões; o público leigo, sempre "preocupado" com a péssima qualidade da educação brasileira também disse o que pensava.

A maior estudiosa da obra de Monteiro Lobato, a professora Dra. Marisa Lajolo (Unicamp), criticou o pedido do MEC e afirmou que os paratextos sugeridos produziriam uma interferência invasiva, dado seu caráter de direcionamento, monitoramento e gerenciamento do ato de ler ${ }^{5}$. Além disso, a professora afirmou a debilidade moral e educativa de uma interferência do politicamente correto na leitura literária - não há qualquer comprovação dos efeitos de leitura x ou y na formação do caráter de um sujeito, afirma. Em momento crucial de seu artigo, Marisa Lajolo pergunta: "Lendo a história, os leitores desenvolvem preconceito con tra os negros e tornam-se intolerantes? [...” E em seguida responde: "Não se sabe".

A contradição entre a Teoria da Recepção que sustenta as críticas de Marisa Lajolo e o argumento mobilizado
5. LAJOLO. “Preconceito e intolerância em Caçadas de Pedrinho", In: http://www. revistaemilia.com.br/mostra. php?id $=30$
EM TESE
BELO HORIZONTE
v. 20
SET.-DEZ. 2014
BRITO. Querelas de ontem, querelas de hoje $[\ldots]$
P. 127-139

Ensino de literatura e de Teoria da Literatura 
é patente. Talvez porque o objetivo de Marisa Lajolo seja, acima de tudo, assegurar a autonomia do texto literário. Seu último argumento diz da capacidade de o próprio texto resolver seus problemas: se em algumas passagens a personagem Tia Nastácia é tratada de forma racista, em outras passagens sua figura é celebrada como a criatura com a mais alta condição de representar a humanidade, destaca Lajolo.

Sem nunca admitir o que precisa ser admitido - de fato, existem passagens no conjunto da obra de Monteiro Lobato em sua literatura infantil, na literatura adulta, em artigos e em sua correspondência pessoal que apresentam explicitamente preconceitos de raça, valores racistas e até defesa da eugenia - Marisa Lajolo desenvolve sua resposta ignorando que talvez seja legítima a recomendação de alguns cuidados, advertências e orientações adequadas aos professores quando da apresentação para as crianças dos trechos de livros em que isso acontece.

Como se vê, nem culturalistas nem hermeneutas, saíram satisfeitos da contenda: os primeiros queriam a suspensão e a proibição dos livros de Monteiro Lobato. A justiça optou pela manutenção dos livros com a recomendação de paratextos. E ainda permaneceram descontentes aqueles que, ao mesmo tempo, defendem o leitor como elemento constitutivo dos sentidos de um texto literário e temem pela interferência de paratextos como se esse leitor idealmente participativo fosse uma figura que já não sofresse inúmeras interferências ideológicas na produção de seus horizontes de expectativas.

Se a ideia é oferecer a oportunidade de que o confronto com o Outro signifique a possibilidade concreta de aguçamento do poder de crítica por parte do público leitor, porque eliminar a experiência de leitura de um texto que, em seu momento histórico não incomodou a elite branca que o lia, mas que hoje, ampliado o público leitor, redefinidos os conceitos de direitos e de democracia, coerentemente (ainda bem) nos incomoda? O que pretendemos, efetivamente, com o ensino de literatura hoje: proteger ou formar leitores?

Mais uma vez a Querela entre Antigos e Modernos oferece eventos pontuais que, justapostos às questões apresentadas, possibilitam reflexões interessantes:

1) Tradicionalmente, a querela entre Antigos e Modernos é explicada como uma contenda que dividiu a República das Letras entre aqueles que acreditavam viver um período de decadência e aqueles que defendiam a era do Rei Sol como o ápice da cultura européia. Um dos principais problemas dessa divisão estava na interpretação do Estado de Luís XIV. Joan Dejean ${ }^{6}$ mais recentemente reavaliou a Querela francesa como uma "guerra cultural" que revela a importância do surgimento, naquele momento, de uma opinião pública. A professora norte-americana aposta que se trata de algo,
6. DEJEAN, Antigos contra Modernos: as guerras culturais e a construção de um fin de siècle, p..35
EM TESE
BELO HORIZONTE
v. 20
N. 3
SET.-DEZ. 2014
BRITO. Querelas de ontem, querelas de hoje [...]
P. 127-139

Ensino de literatura e de Teoria da Literatura 
aparentemente, muito mais abrangente do que a explicação tradicional e defende que estava em jogo a redistribuição do controle das transmissões culturais. Nessa perspectiva é que a polêmica sobre o racismo em Monteiro Lobato pode ser aproximada com a Querela entre Antigos e Modernos.

Levando em consideração que nosso público leitor já está, ao menos em termos constitucionais, ampliado democraticamente pela Escola; um problema subsiste e oferece o ponto de contato: hoje, nós idealizamos formar um leitor emancipado, capaz de fazer escolhas autônomas para sua prática de leitura literária tanto no cânone, sabendo o que é o cânone quanto fora dele; idealizamos também que ele seja capaz de selecionar, dentre os mais diferentes meios de informações de que dispõe, aquelas que compõem uma narrativa coerente com uma visão ética e solidária da vida em comunidade.

Essa formação deve estar apoiada nos clássicos ou não? A formação que nós chamamos de tradicional pressupõe a leitura de textos que, para alguns, está investida de um valor exemplar único; para outros, para aqueles que aspiram ao que chamam de verdadeira democratização da cultura essa formação baseada nos clássicos está e sempre esteve ligada aos privilégios de uma elite. Para os Modernos de hoje, a leitura de textos literários da tradição atravanca o progresso da humanidade rumo a destinos mais igualitários. Eliminar os textos "racistas" de Monteiro Lobato do cânone e, consequentemente, do sistema literário que constitui a vida escolar promoveria um avanço nesse sentido?

A comparação entre querelas de ontem e de hoje nos ajudam a elaborar algumas sínteses, importantes para a autocrítica e para o avanço de nossas estratégias de formação de leitor. Os Modernos, louvando a figura do Rei Sol como o apogeu da história da humanidade, transformavam-no em referência para que os súditos daquele reino, apagando referências históricas que poderiam produzir críticas negativas. Em termos literários, isso significaria apagar as diferenças que porventura textos de diferentes momentos históricos poderiam opor à sensibilidade do honnête homme. Apagar Monteiro Lobato diminuiria a percepção do problema do racismo para o qual se quer uma consciência sempre atenta e vigilante.

Em um contexto em que a técnica, a ciência, a indústria cultural e a globalização econômica operam discursos que convergem para a homogeneização de valores subordinada à lógica do consumo, a lembrança da Querela entre Antigos e Modernos impõe uma exigência ética, que se desdobra em estética: o resgate de nossa capacidade de reconstrução de valores que nos ajudem a identificar diferenças, a entrar em crises com elas e, assim, avançar.

2) O problema da autonomia da obra de arte. M. Dacier, uma helenista francesa muito respeitada na última década 
do século XVII, publicou em 1710 sua tradução pretensamente fiel da Iliada. A tradução de Dacier foi recebida pela Academie de Luís XIV como uma prova da imperfeição bárbara e grosseira da obra Homero. Em revanche, Houdar de La Motte publicou em 1714 sua versão da líada, feita a partir do Latim, que adaptava Homero para o gosto das honnêtes gens, tornando o poema "agradável" para o público leitor. Tinha início assim um inflamado debate sobre Homero, um dos muitos que alimentaram a Querela. La Motte representava os Modernos e Dacier, os Antigos.

Em texto de crítica à tradução de Dacier, La Motte pergunta como ignorar as falhas morais de Aquiles, sua sede de sangue e de glória. Essa pergunta não lembra as críticas dirigidas as Caçadas de Pedrinho? "Como ignorar o racismo de Emília?" perguntam-se os culturalistas.

A postura de quem hoje defende a autonomia do texto literário, por sua vez, também possui afinidade com os Antigos: ambos buscam, buscavam e buscam, uma independência poética do império da Razão e da Ética (no caso do século XVII, da ética cristã). Na defesa de sua tradução quase literal de Homero, Dacier, em vez de tentar vender uma imagem da antiguidade como algo assimilável aos homens de seu tempo, procurava, ao contrário, radicalizar as diferenças: os costumes dos homens daquele tempo imemorial são

bárbaros sim, sua linguagem é popular e grosseira mesmo, e efetivamente Homero não conhecia o deus cristão.

Do mesmo modo, Marisa Lajolo propõe que o texto de Lobato seja apresentado sem os comentários paratextuais que colocam em risco a "pureza" do texto de Lobato. Mas a comparação aqui não tem como objetivo afirmar a correção da professora da Unicamp, a comparação busca antes demonstrar a necessidade de enfrentarmos o estranhamento produzido por valores de outras culturas, esteja a diferença no tempo ou no espaço. Estranhamento formal e estranhamento experiencial podem contribuir imensamente para a formação de uma consciência literária que pode contribuir, por sua vez, para a formação ética do leitor.

\section{A FALSA DICOTOMIA TEORIA X PRÁTICA}

Se um dia os métodos imanentistas nos ajudaram a ler ideologicamente textos literários e não literários, isso significa que a teoria literária ganhou uma relevante tarefa, que devemos manter em atividade: a tarefa de refletir criticamente sobre todas as nossas atitudes como professores - afinal, não há tarefa mais ideologicamente comprometida. Que a ideologia seja, ao menos, consciente. E que a atividade do professor de literatura, orientada pela reflexão teórica, seja sempre um "combate feroz e vivificante [...] contra as ideias preconcebidas"7.
7. COMPAGNON. O demônio da teoria: literatura e senso comum, p. 16. 
Nas escolas brasileiras, não é difícil encontrar o professor que, ao mesmo tempo em que diz "eu não gosto de teoria”, exige a leitura de um livro literário politicamente correto e aplica um questionário para verificação de leitura. Ele não percebe que sua afirmação, ou melhor, sua negação, bem como a escolha da obra e a atividade de avaliação indicam de antemão uma postura teórica e política. $O$ professor pode ter sua negação analisada teoricamente e, além disso, suas concepções, princípios e métodos podem ser colocados em discussão.

A teoria da literatura continua sendo importante para a formação do professor, porque as discussões sobre o literário, em sala de aula ou fora dela, nos oferecem, quase sempre, boas oportunidades de presenciar e avaliar a disputa pelo poder de dizer "isto é literatura" (problema fundamental da teoria), "isto deve ser ensinado" (interesse político no cânone), "esta leitura é importante" (discussão de critérios para a definição do cânone), "este tipo de leitura literária pode prejudicar" (interferências morais e culturais na formação do leitor).

A meu ver, a teoria da literatura faz-se presente e necessária todas as vezes em que determinadas afirmações sobre literatura querem se fazer passar por "naturais" e "evidentes". Um dos objetivos mais específicos dos meus estudos sobre ensino de literatura no Brasil tem sido reunir teoria, crítica e história literária para a construção de uma história das ideias literárias em conflito. Com isso, pretendo contribuir para a formação do professor de literatura que precisa lidar cotidianamente com discursos que nem sempre conseguem enxergar como construções históricas datadas e interessadas politicamente.

\section{OS CAMINHOS DA PESOUISA}

Essas são as ideias que sustentam o projeto de pesquisa registrado na Universidade Federal de Goiás que recebeu o nome de "Crise da literatura e narrativas de crise".

As perguntas fundadoras do projeto podem ser assim sintetizadas:

- Quais sentidos a palavra crise adquire no debate sobre literatura ao longo do século XX?

- Que conceitos teóricos da literatura estruturam o discurso da crise do ensino de literatura?

- O que as querelas literárias do passado têm a nos ensinar sobre crise da literatura?

Seus principais objetivos descrevem-se nas seguintes linhas:

- Avaliação das consequências da circulação dos dois documentos conflitantes - os PCNs de 2002 e de 2006 - nas práticas de ensino dos professores das escolas públicas do Estado de Goiás; 
- Levantamento bibliográfico, leitura e comentário críticos de pensadores dos Estudos Literários que encaminhem propostas de solução para a crise do Ensino de Literatura;

- Mapeamento dos discursos de crise da literatura no Brasi a partir do levantamento de textos cujo caráter querelante possa ser identificado (em primeiro lugar, um texto dessa natureza possui sempre um antagonista explícito - um autor, um artigo, um livro etc.).

\section{REFERÊNCIAS}

CALVINO, I. Por que ler os clássicos. São Paulo: Companhia das Letras, 1993.

CEVASCO, M. E. Dez lições sobre Estudos Culturais. São Paulo: Boitempo, 2003.

COMPAGNON, A. Literatura para quê? Belo Horizonte: Ed. UFMG, 2009.

COMPAGNON, A. O demônio da teoria: literatura e senso comum. Belo Horizonte: Ed. UFMG, 2006.

DEJEAN, J. Antigos contra Modernos: as guerras culturais e a construção de um fin de siècle. Rio de Janeiro: Civilização Brasileira, 2005.

EAGLETON, T. Teoria da literatura. Uma introdução. São Paulo: Martins Fontes, 2003.
FREADMAN, R.; MILLER, S. Re-pensando a teoria: uma crítica da teoria literária contemporânea. São Paulo: Editora UNESP, 1994

TIEGHEM, P. Les grandes doctrines littéraires en France. Paris: PUF, 1993

SARTRE, J.-P. Que é a literatura? Trad. Carlos Felipe Moisés. São Paulo: Ática, 1999.

SAID, E. Humanismo e crítica democrática. São Paulo: Cia das Letras, 2007.

TODOROV, T. A literatura em perigo. Tradução Caio Meira. Rio de janeiro: DIFEL, 2009 